\title{
Adolescentes e mediação da leitura em biblioteca escolar
}

\author{
Flávia Ferreira Abreu \\ Mestre; Universidade Federal de Minas Gerais, Belo Horizonte, MG, Brasil; \\ flaviaabreu2911@gmail.com \\ Ligia Maria Dumont \\ Doutora; Universidade Federal de Minas Gerais, Belo Horizonte, MG, Brasil; \\ dumont@eci.ufmg.br
}

Resumo: A pesquisa investigou as ações de mediação e incentivo à leitura que são utilizadas por equipes de bibliotecas escolares para os adolescentes, com o intuito de formar leitores. O objetivo foi analisar o trabalho do bibliotecário escolar que desenvolve essas ações em seu modo de operar, contribuindo para a formação de sujeitos críticos e com gosto pela leitura. Metodologicamente, empreendeu-se um estudo de casos múltiplos, de abordagem qualitativa, embasado pelo ponto de vista da teoria etnográfica. Na coleta de dados, o ambiente de investigação foi representado por três bibliotecas escolares, uma do ensino privado, e as demais pertencentes à rede pública municipal da cidade de Belo Horizonte - MG, que atendem alunos do ensino fundamental a partir do quinto ano. A observação e as entrevistas semiestruturadas foram utilizadas para a coleta de dados, que tiveram como sujeitos da pesquisa os bibliotecários e professores que participam dessas ações. A pesquisa constatou que as atividades de mediação e incentivo são efetivas quando o mediador é leitor e mantém-se aberto ao diálogo contínuo com seus usuários e com outras instâncias da escola. Constatou-se que as ações mais bem sucedidas e longevas de formação do leitor nas três bibliotecas foram as da mediação promovida pelos encontros ininterruptos dos clubes de leitura, cujos participantes se reúnem para compartilhar leituras por eles escolhidas, pelo prazer de ler. As bibliotecas analisadas têm projetos de mediação e incentivo à leitura com a participação de professores e bibliotecários. A novidade foi a presença de professores de outras disciplinas, que se mostraram grandes mediadores da leitura. Constatou-se, também, o que vários autores da área apregoam, ou seja, bibliotecário e professor são formadores de leitores. No caso específico da pesquisa, são conhecedores da literatura para crianças e adolescentes, dos autores, gêneros literários e, principalmente, planejam-se para compartilhar as leituras, como possibilidade de formar leitores críticos e contextualizados com sua sociedade.

Palavras-chave: Mediação da leitura. Adolescentes. Biblioteca escolar. Leitor crítico. Colaboração bibliotecário-professor. Clubes de leitura. 


\section{Introdução}

A pesquisa ${ }^{1}$ teve como finalidade investigar a leitura e a formação de leitores, com ênfase na mediação e incentivo à leitura empreendida pelo bibliotecário em bibliotecas escolares. Um dos desafios do profissional é promover a formação do leitor de forma criativa e reflexiva, para que ele possa futuramente agir com autonomia na sociedade, visto que a leitura é um processo que possibilita desenvolver o conhecimento e a evolução de um cidadão questionador. $\mathrm{O}$ bibliotecário, por ser um sujeito que trabalha com a informação, pode e deve auxiliar o usuário da biblioteca no caminho da compreensão da informação de diversas formas, inclusive por meio da prática da leitura de lazer.

Almeida Júnior (2007) reflete sobre a importância da leitura para a Biblioteconomia e Ciência da Informação, pois, segundo o autor, sem esse fazer as áreas passam a lidar com um objeto imaginário. Desconsiderar a leitura ou não a entender de forma efetiva é determinar a inviabilidade das duas áreas. Estudar a leitura é uma possibilidade de atualizar os conhecimentos que os profissionais da Biblioteconomia vêm desenvolvendo em suas práticas no exercício do seu trabalho.

A história da leitura é similar a de outras práticas culturais humanas, pois sua constituição está relacionada ao contexto histórico em que cada leitor vivenciava ao interpretar as variadas tipologias textuais. Dumont (1998, p. 56) salienta que "entre os vários conceitos para o estudo da leitura, cabe destacar os de contexto, o sentido e a motivação". Especificamente ao conceito de contexto e leitura, a autora explica que:

\footnotetext{
Não se trata de estudar as leituras realmente praticadas de uma obra, ou de outra, em determinada época, ou em outra. Trata-se sim de examinar como um texto se expõe, explicitamente ou não, à leitura, ou as leituras que dele são feitas ou podem ser feitas, em outras palavras, como se permite a liberdade de leitura, ou se faz sua restrição (DUMONT, 1998, p. 56).
}

Acredita-se que dessa forma o ato leitura pode ser entendido, tendo por base diversos olhares que proporcionarão uma visão para o entendimento das formas e componentes do seu desenvolvimento. Nesse sentido, o bibliotecário, 


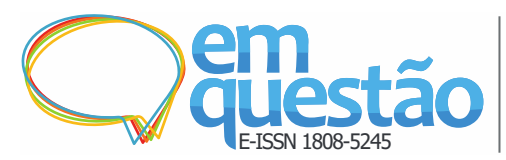

Adolescentes e mediação da leitura em biblioteca escolar Flávia Ferreira Abreu, Ligia Maria Moreira Dumont

como agente formador de leitores, necessita de ter ciência desse arcabouço teórico e trabalhar com o intuito de transmitir os benefícios que a leitura pode provocar no desenvolvimento de uma pessoa. O bibliotecário deve desenvolver habilidades para que possa mediar a leitura e para tal, necessita conhecer seu leitor e as fontes de informação e, principalmente, ser leitor.

Bicheri e Almeida Júnior (2013, p. 48) atestam que um dos requisitos para mediar a leitura em bibliotecas escolares "é ser leitor e dar testemunho disso aos alunos; não só disponibilizar leitura aos seus usuários, mas também propor-lhes leituras", visto que a capacidade de ler desencadeia todo o processo de conhecimento de mundo. Tal constatação foi sinalizada por Freire (1989, p. 9), ao afirmar que a "leitura do mundo precede a das palavras". Desde o nascimento as pessoas interagem com elos culturais, que proporcionam a construção da identidade individual e coletiva. Essa relação com o outro permite que os indivíduos se conheçam e, por meio das semelhanças, do compartilhamento, sintam-se pertencentes à determinada cultura coletiva.

É nessa perspectiva que a pesquisa propôs o estudo, sob o enfoque da biblioteca escolar, ou seja, como as ações de mediação e incentivo à leitura têm sido realizadas por equipes de profissionais de bibliotecas escolares das instituições de ensino privado e público municipal de Belo Horizonte, Minas Gerais, referente aos alunos adolescentes do ensino fundamental a partir do quinto ano, e de que forma essas ações podem contribuir para apropriação da informação por meio da leitura. Para compreender tal questão foi traçado o seguinte objetivo geral: investigar o trabalho do bibliotecário escolar que desenvolve ações de mediação e incentivo à leitura em seu modo de operar ou agir, visando identificar as características mais marcantes que podem colaborar para a formação de leitores.

Para tal, analisaram-se quais as ações de mediação e incentivo à leitura são desenvolvidas nas bibliotecas escolares investigadas e quais se destacavam como incentivadoras do aprendizado de apropriação da informação pela leitura. Portanto, averiguaram-se, na prática, quais competências os bibliotecários possuem e utilizam para mediar a leitura e formar leitores pressupostamente aptos a se inserir e participar da sociedade, de forma ativa e consciente. Nesse 


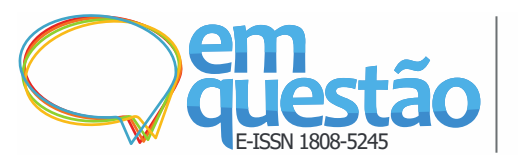

Adolescentes e mediação da leitura em biblioteca escolar Flávia Ferreira Abreu, Ligia Maria Moreira Dumont

sentido, visava, também, verificar se o desenvolvimento de trabalho incluía a participação de professores e o pessoal da biblioteca nas ações de mediação e incentivo à leitura, a partir dos alunos do quinto período fundamental.

Rasteli (2013), observou que as pesquisas direcionadas para os anos iniciais do ensino fundamental têm apresentado conquistas expressivas, mas segundo Ceccantini (2009), os estudos atestam, ainda, que há um abandono de atos de incentivo e mediação à leitura, a medida que os leitores recém-cultivados vão deixando a infância. Por acreditar que tal constatação não é a ideal para incentivar o gosto contínuo pela leitura, escolheu-se pesquisar ações de leitura que atendam alunos do Ensino Fundamental, com turmas a partir do quinto ano para o estudo referente às ações de incentivo e mediação à leitura.

\section{Referencial teórico}

$\mathrm{O}$ arcabouço teórico da pesquisa foi estruturado por temas importantes para a compreensão das ações desenvolvidas pelo bibliotecário como incentivador, mediador da leitura, perpassando por conceitos como mediação, leitura, colaboração, gosto pela leitura, leitor crítico e questionador. Destaca-se, portanto, o papel do bibliotecário como profissional que incentiva o desenvolvimento do gosto pela leitura, atuando na formação de pessoas inseridas ativamente na sociedade.

Certamente, esse enfoque movimenta-se por outras áreas de estudo como a educação, a pedagogia, a literatura e a sociologia, pois a leitura é uma ação social, desenvolvida por atores em determinados contextos. Portanto, para compreender o processo de mediação da leitura, é preciso ampliar o conhecimento retratado na literatura referente a estes dois conceitos, suas origens, usos, para então levá-los e interpretá-los à luz das áreas da Ciência da Informação e da Biblioteconomia. A literatura sobre mediação e leitura tem se desenvolvido substancialmente nas últimas décadas, portanto, apresenta-se um recorte que reflete, genericamente, questões básicas para o alicerce deste artigo. 


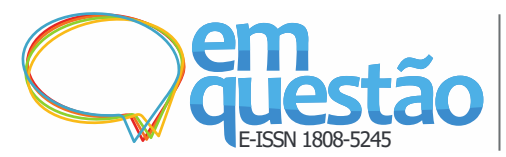

Adolescentes e mediação da leitura em biblioteca escolar Flávia Ferreira Abreu , Ligia Maria Moreira Dumont

\subsection{Leitura e leitor}

Praticamente impossível definir separadamente conceitos para leitura sem a perspectiva do leitor, eles encontram-se intrinsecamente ligados. Dumont (2007) realizou levantamento histórico sobre os estudos da leitura e verificou que o movimento neste sentido iniciou nos Estados Unidos, no contexto da crise econômica do final da década de 1930, embasado na sociologia da leitura. Os estudos sobre difusão da leitura e os efeitos sobre o leitor reuniram, no mesmo sentido, as ações dos literatos, educadores, bibliotecários, pedagogos, psicólogos e sociólogos. Um pouco mais tarde, em 1950, os franceses iniciam as pesquisas voltadas para a promoção e uso da partilha dos textos. A partir da década de 1980, os estudiosos passam a ter um olhar direcionado ao público leitor ou receptor de informações. A autora salienta, ainda, que nas últimas décadas surgiram indagações dos estudiosos da Ciência da Informação e da Biblioteconomia para compreender o contexto social e, assim, o fluxo de informações, o sujeito e a diversidade da leitura nessas duas áreas. Atualmente, as pesquisas se preocupam em identificar a efetividade e introjeção de conhecimentos pela leitura, entendida como apropriação da leitura, a partir da subjetividade do leitor e, notadamente, pelo seu contexto.

Ao remontar a história da leitura, Cavallo e Chartier (1998) destacam as diferenças, singularidades e as diversas maneiras de ler, que caracterizam as sociedades ocidentais desde a Antiguidade:

Reconstruir em suas dimensões históricas tal processo exige, em primeiro lugar, considerar que suas significações dependem das formas e das circunstâncias por meio das quais os textos são recebidos e apropriados por seus leitores (ou seus ouvintes). Estes últimos nunca são confrontados com textos abstratos, ideais, desligados de qualquer materialidade: eles manipulam objetos, ouvem palavras cujas modalidades governam a leitura (ou a escuta) e, ao fazê-lo, comandam a possível compreensão do texto - que habitou a crítica estruturalista, em todas as suas variantes, mas também as teorias literárias mais preocupadas em reconstruir a recepção das obras (CAVALLO; CHARTIER, 1998, p. 6).

O leitor é, no sentido de apropriação, sujeito produtor de significados, a partir do estímulo da leitura. Nessa perspectiva, a percepção que se tem do sujeito é vista como a desejada produção de conhecimento, resultando, em geral, 


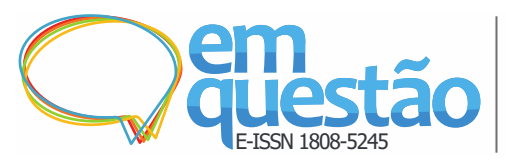

Adolescentes e mediação da leitura em biblioteca escolar Flávia Ferreira Abreu, Ligia Maria Moreira Dumont

em atuação pessoal e social transformadora. A ação leitura é um processo exercido única e individualmente por cada leitor, ao dar sentido ao que leu. E esse sentido pode variar bastante de leitor para leitor. Dumont (1998, p. 65) enfatiza: "a apropriação do texto pelo leitor implica na produção de sentido, que é onde se imprime a singularidade da leitura, baseada na experiência individual de cada leitor".

Antunes (2003, p. 70) acredita que:

\begin{abstract}
A atividade da leitura favorece, num primeiro plano, a ampliação dos repertórios de informação do leitor. Na verdade, por ela, o leitor pode incorporar novas ideias, novos conceitos, novos dados, novas e diferentes informações acerca das coisas, das pessoas, dos acontecimentos, do mundo em geral. (ANTUNES, 2003, p. 70)
\end{abstract}

Pode-se definir a leitura como uma forma de o leitor compreender o texto a partir de seu conhecimento interno e sua relação com o saber, que vem adquirindo a partir das diversas leituras que faz do mundo. A leitura é um direito de todos os cidadãos, que pode ampliar os horizontes críticos e culturais do homem. Nesse sentido, as pessoas podem desenvolver de forma mais efetiva o senso crítico e conquistar decisões desejadas para si e seu convívio social.

Já se tratando da leitura na escola, Britto (2015, p. 40) esclarece que, primeiramente, é para ensinar e aprender a ler, devendo os profissionais da escola "investir no leitor e na valorização de suas escolhas e decisões de caminhos interpretativos". A partir de escolhas dos alunos por textos de literatura, história, ciência, cabe à escola a formação de um leitor livre, que age conforme sua vontade, consciência e natureza, tendo limites conforme suas dimensões biológicas, materiais e históricas. O leitor autônomo capaz de se autogovernar a partir da apropriação "das formas de ser e de fazer o mundo e se reconhecendo como sujeito de direito, reivindica para si o poder de tomar decisões relativas à sua vida" (BRITTO, 2015, p. 43). A autonomia é medida pela capacidade de analisar, compreender a situação com conhecimento e discernimento próprio. O leitor crítico fará uma análise objetiva do problema, sem dogmas, preconceitos, contribuindo para o desenvolvimento do sujeito e para a expansão do conhecimento, apresentando sua contrapalavra. 


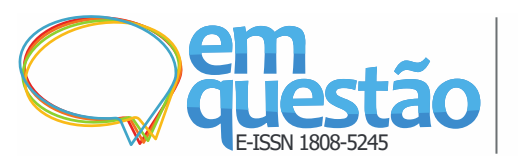

Adolescentes e mediação da leitura em biblioteca escolar Flávia Ferreira Abreu , Ligia Maria Moreira Dumont

Os indivíduos na sociedade, por meio de uma visão e conhecimento críticos possibilitados pela leitura reflexiva e a apreciação do sistema social, têm condições mais efetivas de decidir sobre as questões do seu entorno, visto que é um direito o acesso às informações públicas do Estado, por exemplo. Para isso, ser leitor é um ponto positivo para conhecer a sociedade, podendo passar a agir de forma mais atenta e também democrática.

\subsection{Mediação}

De acordo com a teoria histórico-social de Vygotsky (1993), as interações sociais são essenciais para a constituição dos indivíduos e, durante a vida do homem, o conhecimento acumulado ocorre em um processo de mediação entre os indivíduos. No contexto escolar, tal perspectiva redimensiona a relação entre os envolvidos na mediação e estímulo à ação leitura, o que implica no diálogo que possibilitará o compartilhamento das discussões, das ações e comentários realizados durante o processo de construção do conhecimento, ao favorecer as trocas de ideias e as conversas, que vão acontecendo e se desenvolvendo como capital intelectual humano.

Turra (2007) define mediador como a pessoa que avalia, amplia e escolhe estratégias mais apropriadas a determinado contexto, organiza, interpreta e elabora as experiências de aprendizagem. Ao criar um ambiente de reciprocidade, o mediador suscita curiosidade, demonstra envolvimento e interesse, estimula a reflexão, o compartilhamento e o apreço pelas diversas opiniões, incitando, ainda, a mudança e a participação ativa. Quanto maior a mediação, maior a possibilidade de transformar o estado cognitivo do sujeito mediado. A autora conclui o artigo afirmando que

O processo de mediação vai além de uma simples e orientada tarefa, de um produto, de uma orientação de aprendizagem; objetiva tornar o indivíduo capaz de agir independentemente de situações específicas e isso torna o sujeito capaz de se adaptar às novas dimensões com as quais ele irá se defrontar. (TURRA, 2007, p. 309).

Marteleto (2009), informa que a ideia de mediação, numa perspectiva difusionista do conhecimento científico, foi desenvolvida nos anos 1970. 


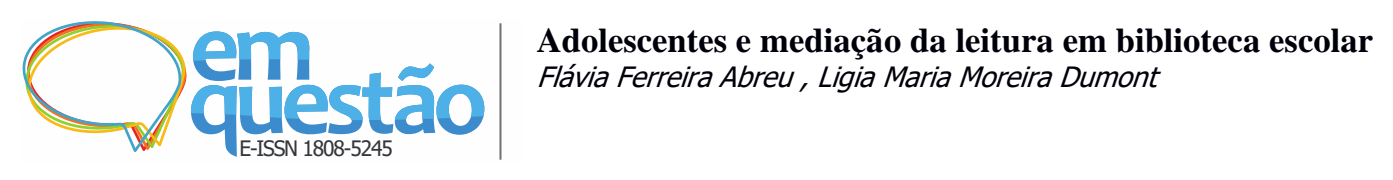

No entanto, hoje ela assume as seguintes características: a) não se trata mais da ciência enquanto tal; b) as formas de discursos estudadas são muito diversas, longe do modelo unificador da vulgarização; c) a abordagem pragmática da informação e da comunicação torna-se predominante em relação à abordagem crítico-denuncista dos anos de 1970. (MARTELETO, 2009, p. 20).

Informa, ainda, Marteleto (2009), que o "como fazer" toma o lugar do "para que". Logo, pensa-se mais em um "compartilhamento entre os saberes" do que em um "compartilhamento de saberes", que os estudos das ciências da Comunicação e da Informação vêm se dedicando a investigar. $\mathrm{O}$ conceito de mediação, ao privilegiar uma análise relacional do conhecimento e das informações, leva em conta que existe uma negociação entre as propriedades do discurso proposto e as estratégias de apropriação dos sujeitos sociais. A autora cita Gellereau (2006), ao estabelecer que o termo "pode ser entendido sob dois prismas: o de "relação com um sistema" (ex. a mediação social) ou o de “construção de sentido (GELLEREAU, 2006² apud MARTELETO, 2009, p. 19). Marteleto considera, seja numa ou noutra acepção, a "mediação implica sempre em acompanhamento, controle e negociação por um 'terceiro', enquanto o sujeito que se beneficia de um processo de mediação é levado a aprofundar o seu próprio ponto de vista e a descobrir outros" (MARTELETO, 2009, p. 20). Relembra, ainda, que o conceito do termo leva em conta a existência de uma negociação entre as propriedades do discurso proposto e as estratégias de apropriação dos sujeitos sociais.

Em publicação mais recente e apontando especificamente os estudos da informação e comunicação, Marteleto e Couzinet (2013, p. 3) assinalam que a

[...] noção de mediação veio se transformando nos últimos anos, passando da ideia de transmissão unilinear, concebida nas teorias clássicas e alicerçada na figura de um mediador ou de uma mídia, a um processo onde intervêm diferentes agentes técnicos, sociais e culturais. Outro ponto relevante foi a amplitude da abordagem do objeto no campo da informação: antes limitado ao estudo da "informação científica" e seus processos de transmissão, novos estudos passaram pouco a pouco a incorporar outras práticas por meio das quais os saberes e as informações são produzidos e apropriados socialmente, compreendendo a riqueza e a dimensão criativa dos mediadores enquanto atores da transformação cultural e a importância das mediações na instituição da cultura e da sociedade. (MARTELETO; COUZINET, 2013, p. 3). 


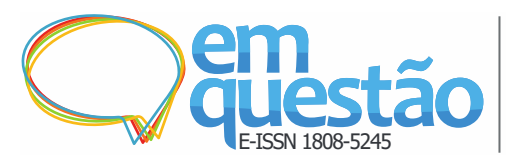

Adolescentes e mediação da leitura em biblioteca escolar Flávia Ferreira Abreu, Ligia Maria Moreira Dumont

Também Araújo (2016) reforça a crítica ao modelo transmissivo dos anos iniciais dos estudos de mediação e a Ciência da Informação, relembrando a tríade conceitual dado-informação-conhecimento hegemônica nos anos 1990 e a aproximação aos conceitos de cultura e mediações. Reforça, ainda, que a noção de mediação convoca os estudiosos da Ciência da Informação a olhar para as "distintas intervenções humanas (institucionalizações, sedimentações, acumulações, apropriações, concordâncias, resistências), entendidas não apenas como 'operações técnicas' (com um sentido nelas mesmas)".

O autor destaca com propriedade que a Biblioteconomia e a Ciência da Informação precisam cada vez mais se descolar dos estudos fisicistas das décadas de 1960 e 1970 que se encontram ultrapassados, pois as práticas de mediação da informação não são efetivas caso não se espelhem nas facetas históricas, políticas, econômicas e sociais do contexto, da comunidade a qual os seus leitores pertencem.

\subsection{Mediação da leitura}

Em 2007, Almeida Júnior ressaltou que "mediação é uma palavra ainda fora do vocabulário da Biblioteconomia, ou, quando muito, sinônimo de serviço de referência" (ALMEIDA JÚNIOR, 2007, p. 39). O autor traz também a concepção de que a "leitura é individual, distinta de outras leituras, pois não pode abstrair-se dos referenciais de quem a realiza" (ALMEIDA JÚNIOR, 2007, p. 39). Salienta ainda, que similar à "informação, a leitura não existe $a$ priori, concretiza-se no processo de mediação. A mediação da leitura faz parte da mediação da informação" (ALMEIDA JÚNIOR, 2007, p. 35).

Passados alguns anos, o termo mediação da informação foi adotado, ganhou corpo e atualmente está sendo muito utilizado na literatura brasileira da Biblioteconomia e da Ciência da Informação. No entanto, considera-se que para sua consolidação, a adoção do termo necessita maior fundamentação, no tocante às questões relacionadas à motivação da leitura e formação do leitor.

Acredita-se que ainda é preciso pensá-lo com certa inquietação, haja vista que o termo mediação foi tomado emprestado, mais especificamente das 


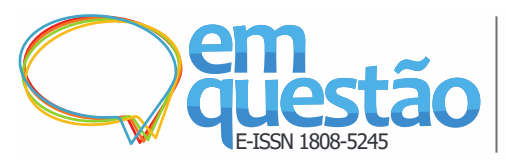

Adolescentes e mediação da leitura em biblioteca escolar Flávia Ferreira Abreu , Ligia Maria Moreira Dumont

áreas Educação e Comunicação, logo, precisa ser devidamente incorporado na fundamentação teórico-conceitual da Ciência da Informação e da Biblioteconomia, ter seus próprios alicerces, legitimar-se como objeto. Se a leitura pressupõe a introjeção de conhecimentos próprios, exclusivos e sob a perspectiva única do sujeito leitor, o significado da palavra mediar ainda necessita melhor adequar-se à ação leitura, que já possui boa sedimentação teórica. O conceito geral de mediação apresenta ainda resquício tecnicista, a saber, a ação sofre a influência do emissor na linearidade da emissão da informação. Certamente isso pode acontecer com leitores em fase de formação, daí a precaução em bem explicitar o uso da expressão mediação da leitura, mas não no leitor maduro.

Em contraponto, torna-se importante refletir que as ciências contemporâneas apresentam a característica de fronteiras disciplinares um tanto menos rígidas, possibilitando uma aproximação entre áreas distintas. Nunes e Cavalcante (2017, p. 5) reforçam:

[...] com o passar dos anos, a temática da mediação tem se expandido, passando a inspirar outras questões para além do papel exercido pela biblioteca na sociedade. Atualmente, muitos são os campos de pesquisa na CI onde se busca aplicar o conceito de mediação, dotando-o de uma relevância cada vez maior. Um sinal dessa relevância é a diversidade de grupos de pesquisa existentes no Brasil relacionados à temática, a qual é destacada já em suas nomenclaturas. (NUNES; CAVALCANTE, 2017, p. 5).

Isso posto, verifica-se que é recente o uso do termo "mediação da leitura" por autores da área de Biblioteconomia e Ciência da Informação no Brasil e que há maior ênfase no uso do termo em práticas da motivação da leitura e no papel do bibliotecário mediador. A pesquisa bibliográfica encontrou a primeira citação no ano 2005, em um trabalho de conclusão de curso de Biblioteconomia (MARTINS, 2005). Os autores Barros, Bortolin e Silva (2006, p. 17) caracterizaram o processo: “[...] mediar leitura é fazer fluir a indicação ou o próprio material de leitura até o destinatário-alvo, eficiente e eficazmente, formando leitores".

Almeida Júnior e Bortolin (2009) descrevem o mediador como um leitor atento, respeitoso e desprendido de preconceitos, sendo um paradigma a ser 


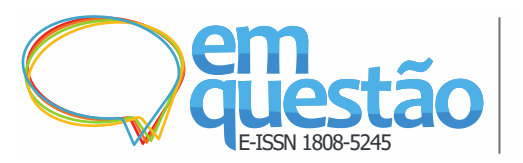

Adolescentes e mediação da leitura em biblioteca escolar Flávia Ferreira Abreu , Ligia Maria Moreira Dumont

seguido, sem deixar, porém, de revelar as suas preferências. Eles ressaltam, ainda, em publicação do mesmo ano, que leitor narrador ou ouvinte está continuamente em processo ativo, "pois ora somos mediadores, ora somos mediandos, numa troca de papéis mais do que enriquecedora - salutar; principalmente em um país que apesar de avançar estatisticamente o número de leitores, ainda não está satisfeito, e quer mais" (BORTOLIN; ALMEIDA JÚNIOR, 2009, p.1).

Em estudo posterior, Bortolin (2010, p. 115) ressalta que “o bibliotecário não pode se esquivar da mediação da leitura, visto que o ato de ler precede o ato de se informar, descobrir e investigar. Portanto, a tarefa de mediar leitura é tão fundamental quanto disponibilizar documentos (impressos e eletrônicos) aos leitores de uma biblioteca". Defende que o bibliotecário, além de se preocupar em organizar a informação, estando ela impressa ou em rede, deve ter iniciativas que levem o leitor a apropriação da informação, por meio da leitura. Defende, ainda, a mediação da informação pela oralidade, narração de textos, ou seja, a mediação se faz também fora da leitura "direta" de um texto.

Rasteli (2013, p. 15) identificou

[...] inquietações na Ciência da Informação (CI), em conceber as bibliotecas como espaços de apropriação cultural, de informação, portanto, de conhecimento e desenvolvimento da leitura e, consequentemente, de transformação social. É notório que não basta saber ler, tem-se que desenvolver a capacidade de usar a competência para a leitura no cotidiano, mediante a compreensão do que é lido. Portanto, as práticas de leitura devem desenvolver formas satisfatórias e as habilidades necessárias ao uso do conhecimento para entender, compreender e apreender. (RASTELI, 2013, p. 15).

Há maior número de trabalhos na literatura direcionados ao mediador da leitura, principalmente aos bibliotecários atuantes em bibliotecas escolares e públicas. O bibliotecário escolar, como mediador, deve estar "inserido na comunidade escolar, conhecer e participar das propostas curriculares e fazer da biblioteca um espaço integrado à escola, proporcionando momentos de descoberta, alegria, criatividade, reflexões, debates, questionamentos, aprendizagem e prazer, entre outros" (BICHERI, ALMEIDA JÚNIOR, 2013, p 


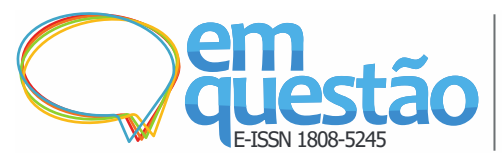

Adolescentes e mediação da leitura em biblioteca escolar Flávia Ferreira Abreu, Ligia Maria Moreira Dumont

47). Acredita-se que colaborar para a formação do cidadão é atitude que faz do bibliotecário escolar um importante agente de transformação social.

Carvalho (2016) reflete que para ser mediador da leitura - seja o professor, seja o bibliotecário - é comum perpassar por incertezas ao decidir responder às necessidades e expectativas imediatas do educando, com respostas objetivas e textos informativos. O mediador deve ser capacitado para realizar a efetiva mediação da leitura, pois o leitor não consome de forma passiva um texto, mas apropria-se, interpreta-o, altera seu sentido a partir dos conhecimentos prévios que tem, construindo sua própria leitura. Para a autora, deve-se ter também o cuidado para que a leitura não passe de um gesto asséptico de alienação e conformismo, e sim de questionamento para os leitores.

Entende-se que a ênfase percebida na literatura quanto à mediação da leitura tem como fundamento a possibilidade de transformação do entendimento do texto pelos leitores segundo seu olhar. Por meio da interação entre os sujeitos envolvidos no processo de construção do conhecimento e do compartilhamento de ideias, instaura-se a possibilidade de diálogo e a formação de convicções e questionamentos sobre a realidade em que o sujeito leitor está inserido. Mas mediar não é o mesmo que facilitar. Pode-se considerar que mediar a leitura significa intervir para aproximar, conhecer para apropriar-se do saber. São destacadas as atribuições que devem permear a ação do bibliotecário como mediador da informação, destacando que ele deve instigar, por meio do diálogo e das conversas entre os pares, a construção de novas opiniões e até mesmo de conhecimento. Tal tema de interesse para pesquisa desenvolvida e descrita neste artigo, possui representatividade substancial na literatura da área.

\subsection{Colaboração entre bibliotecário e professor}

A literatura sobre a questão do trabalho conjunto dos dois profissionais é bastante enfática ao apontar que compete ao bibliotecário e à equipe pedagógica dos setores de ensino estabelecer uma colaboração mútua, unindo esforços, imaginação e criatividade, para trabalhar em conjunto em prol do aprendizado do aluno. Silva (1991) acredita na parceria entre o profissional atuante em 


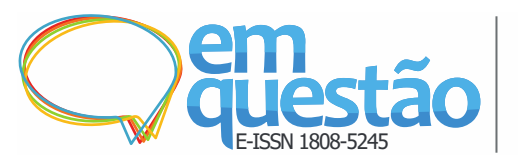

Adolescentes e mediação da leitura em biblioteca escolar Flávia Ferreira Abreu , Ligia Maria Moreira Dumont

biblioteca escolar e o professor quando se trata de leitura, cada um em uma função específica: o primeiro deve priorizar as condições para que a criança aprenda a ler e o segundo deve estar integrado ao professor, cooperando para que a criança desenvolva suas capacidades de leitura e pratique em sua vida "o ler para aprender".

O bibliotecário escolar (leitor, mediador e educador), inserido em sua comunidade, tem como uma de suas atividades participar do projeto pedagógico "atuando junto a professores, alunos, funcionários e familiares de alunos, num trabalho de cooperação e participação, de forma a tornar a biblioteca escolar um espaço dinâmico na escola, favorecendo o processo de ensino-aprendizagem" (BICHERI; ALMEIDA JÚNIOR, 2013, p. 44).

Campello (2009) alerta para as pesquisas que têm revelado os equívocos das atividades aleatórias de práticas da leitura, que partem do princípio de que o importante é ler, não importa o quê, é criar o "gosto" da leitura por meio de técnicas de animação. Para a autora, a biblioteca pode ser um espaço no qual se forma o leitor, desde que seja um espaço de criação e de compartilhamento de experiências, um espaço de produção cultural. Reforça a questão dos bibliotecários e mediadores serem leitores críticos, aptos para o confronto de pensamentos com os usuários através da literatura, sem cobranças mecânicas de compreensão de texto lido e sem fórmulas rígidas de indicação por idade.

Soares (2009), pensadora da área pedagógica, também indica, pela perspectiva do letramento escolar, que o sujeito que aprendeu a ler não apenas lê e escreve, mas é capaz de utilizar-se da leitura e da escrita para interagir criticamente com o seu meio social. Ampliando esse raciocínio, entende-se que o acesso à leitura literária leva o indivíduo ainda mais longe: permite-lhe conhecer a si mesmo e ao universo do qual faz parte, sendo, pois, decisiva para o seu enriquecimento social, afetivo, ético e estético. Em outras palavras, à literatura, como forma de arte, cabe um papel potencialmente humanizador do sujeito leitor.

Segundo Pereira e Campello (2016), há evidências de que a colaboração entre o bibliotecário e o professor é essencial para o desenvolvimento da 


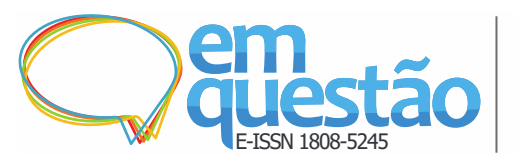

Adolescentes e mediação da leitura em biblioteca escolar Flávia Ferreira Abreu , Ligia Maria Moreira Dumont

aprendizagem da leitura na biblioteca. As autoras desenvolveram um estudo baseado na análise textual de vários artigos de Montiel-Overall e colaboradores, que descrevem o modelo Teacher-Librarian Collaboration (TLC). Os resultados apontam que o trabalho de modelagem utiliza níveis de categorias de colaboração entre o bibliotecário e o professor a partir de coordenação, cooperação, instrução integrada e currículo integrado:

a) coordenação: envolve práticas de colaboração simples, como agendar horário de uso da biblioteca, focando mais na eficiência do que na aprendizagem;

b) cooperação: implica em nível mais alto de intencionalidade e requer mais do que fazer as coisas certas, mas, também, saber trabalhar com o outro, ambos guiados por um propósito comum, como compartilhar responsabilidades em projetos desenvolvidos por estudantes. O bibliotecário pode ser um apoio para o professor, ao selecionar materiais para uso em sala de aula;

c) instrução integrada: o bibliotecário e o professor estão focados no planejamento e implementação de ações que visam à aprendizagem, com base tanto em conteúdos curriculares quanto em habilidades informacionais. Dessa forma, a parceria permite produzir experiências significativas de aprendizagem para os estudantes;

d) currículo integrado: ocorre quando as práticas de colaboração atingem total articulação com as atividades da biblioteca e com o currículo, envolvendo os professores. O bibliotecário vai desenvolver as atividades da biblioteca que integram a base do currículo a partir do planejamento, implementação e avaliação em conjunto com o professor. A direção tem o papel de proporcionar espaço para a colaboração e enxergar o bibliotecário como um professor, dentro das suas especialidades.

Enfatiza-se, para que todo esse processo de acesso à leitura e à informação possa se concretizar, é necessário que haja políticas públicas efetivas e estruturadas, para que profissionais capacitados sejam mediadores nos espaços e ambientes de acesso à leitura e a informação, visando a formação de um cidadão capaz de exercer seus direitos sociais e políticos de maneira consciente. 


\section{Metodologia}

A pesquisa desenvolvida nas bibliotecas escolares de Belo Horizonte que oferecem o ensino a partir do quinto período, caracterizou-se pelo caráter qualitativo e abordou um recorte referente às bibliotecas escolares da rede pública municipal e privada, com o intuito de identificar e analisar as ações de mediação e incentivo à leitura desenvolvidas nessas bibliotecas. Para tal, verificou o desenvolvimento de trabalho em equipe com a participação de professores e bibliotecários no processo de mediação e incentivo à leitura. Por fim, mas não menos importante, investigou as competências em informação que o bibliotecário utiliza para desenvolver a formação de leitores, na perspectiva de estarem aptos a se inserirem e exercerem uma participação mais ativa e consciente na sociedade.

\subsection{Pesquisas similares}

Dentre as pesquisas similares mais próximas sobre mediação da leitura em bibliotecas escolares desenvolvidas na década de 2010 cita-se Rasteli (2013), que pesquisou sobre a mediação de leitura em bibliotecas públicas da Região Administrativa de Marília, São Paulo. A dissertação questiona o caráter dessas ações do ponto de vista daquilo que se distingue como "apropriação da leitura", "promoção da leitura" e "animação da leitura". O pesquisador apurou, que

\footnotetext{
[...] apesar de ser considerada uma área atraente e instigante por esses profissionais, verificou-se pouco interesse e desestímulo da parte desses, no sentido de exercerem efetivamente as funções de agentes culturais, supondo-se que se sintam despreparados, sem as competências específicas e sem estímulos para assumirem tal função. (RASTELI, 2013, p. 136).
}

Deduz-se que, como as atividades oferecidas nas bibliotecas pesquisadas não possuíam frequência pré-determinada, as ações voltadas para a promoção da leitura não demonstraram clara distinção entre elas.

Já Félix (2014), trata das práticas educativas desenvolvidas em bibliotecas escolares da Rede Municipal de Educação de Belo Horizonte. O viés analisado direcionou-se à cultura escolar e discute os fatores que favorecem a 


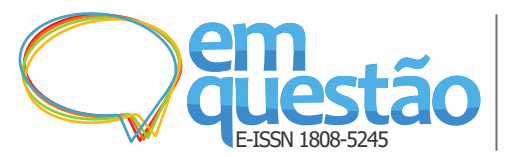

Adolescentes e mediação da leitura em biblioteca escolar Flávia Ferreira Abreu , Ligia Maria Moreira Dumont

evolução de bibliotecas efetivas, como espaços que ofertam condições de acesso ao acervo bibliográfico, mas que também se constituam como lugar de aprendizagem. Metodologicamente, foi realizado um estudo qualitativo em profundidade, com dados coletados a partir de entrevistas semiestruturadas com professores e bibliotecários das escolas pesquisadas. A partir da vertente interpretativa foram revelados três importantes fatores, a saber, a existência de uma cultura escolar colaborativa entre professor-bibliotecário e uma estrutura educacional específica, que dá suporte à biblioteca e à constituição desse espaço como diferenciado pelo apoio e presença dos diretores no setor. $\mathrm{O}$ desempenho da biblioteca é impactado positivamente, Tais elementos articulados mostram que há um ambiente cultural escolar favorável, que permite a existência de uma biblioteca efetiva.

Também Moreira (2014) investigou as práticas educativas bibliotecárias para formação de leitores, por meio do trabalho colaborativo entre o bibliotecário e o professor destas instituições de ensino municipais de Belo Horizonte A autora destaca que foi em torno e a partir de 1985 que aparece nas publicações a preocupação com a orientação social do trabalho com a leitura e o trabalho na biblioteca nesta perspectiva, entendida então como espaço de informação e cultura. Também é a ocasião em que aparece pela primeira vez o termo "ação de leitura" e "prática de leitura". Conclui que a pesquisa realizada na literatura indica que não há, consolidada, uma prática bibliotecária de promoção de leitura e menos ainda a prática educativa bibliotecária de formação de leitor.

Pelo levantamento bibliográfico realizado em fontes brasileiras, o tema ações de motivação e leitura desenvolvidas por bibliotecários em bibliotecas escolares que atuam com alunos acima do quinto período ainda é escasso na literatura, tanto direcionado às questões teóricas, como a relatos de experiências. Tal fato certamente é um dos fatores que refletem no ainda incipiente trabalho do profissional que se encontra na linha de frente das bibliotecas do país, em destaque as públicas e escolares. 


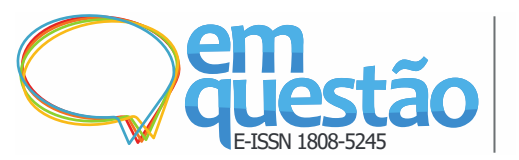

Adolescentes e mediação da leitura em biblioteca escolar Flávia Ferreira Abreu , Ligia Maria Moreira Dumont

\subsection{Sujeito da pesquisa}

Minayo (2009) compreende que a pesquisa qualitativa dá respostas a questões muito específicas, a saber, nas Ciências Sociais, com um nível de fatos que não pode ou não deveria ser quantificado. O trabalho científico em pesquisa qualitativa perpassa por três etapas: a fase exploratória; o trabalho de campo; a análise e o tratamento do material empírico e documental.

Nesse sentido, como estratégia de escolha dos casos estudados, foi feita a seleção de três instituições de ensino, a saber: duas escolas públicas municipais e uma privada, localizadas em Belo Horizonte, Minas Gerais, as quais ofereceram abertura para a pesquisa, além de apresentarem, no dia a dia de trabalho, ações de mediação e incentivo à leitura.

O estudo tomou por base uma amostra não probabilística, qual seja, a amostragem por julgamento. Nesse tipo de escolha estatística classifica-se a amostra intencional, selecionando por interesse e responsabilidade do pesquisador (LAKATOS; MARCONI, 1996), complementando com a técnica de estudo de casos múltiplos.

Os sujeitos da pesquisa foram representados pela equipe da biblioteca e por professores das instituições analisadas. Através da observação realizada nas bibliotecas e da conversa a priori com bibliotecários, foram escolhidas três bibliotecárias e oito professoras que desenvolvem projetos em conjunto às atividades da biblioteca.

\subsection{Campo de estudo}

A Escola Pública Municipal $\left(\mathrm{MA}^{3}\right)$, situada em um bairro de classe média em Belo Horizonte, é uma instituição que atende cerca de 750 alunos do Ensino Fundamental I, II, a Educação de Jovens, Adultos - EJA, além de também abrigar a Biblioteca $\mathrm{Polo}^{4}$, mas que por ocasião da pesquisa in loco encontra-se sem bibliotecário. Em 2014 a equipe da biblioteca optou por atuar junto aos estudantes do sexto ao nono ano do Ensino Fundamental, uma vez que esse público realizava menos empréstimos de livros na biblioteca e com menor frequência se comparados aos demais alunos da escola. 


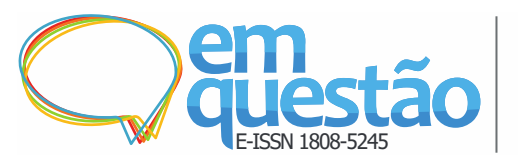

Adolescentes e mediação da leitura em biblioteca escolar Flávia Ferreira Abreu , Ligia Maria Moreira Dumont

A Escola Pública Municipal $\left(\mathrm{MB}^{5}\right)$, localizada também em um bairro de classe média, de Belo Horizonte, conta com as mesmas modalidades de ensino de (MA) e atende aproximadamente 1.000 alunos. A bibliotecária dessa unidade atua com a carga horária de 40 horas semanais, lotada nessa escola, denominada "Escola Polo", de onde acompanha e assiste as outras quatro bibliotecas, com visitas regulares.

$\mathrm{O}$ colégio $\left(\mathrm{EP}^{6}\right)$ é uma unidade de ensino particular que atende aproximadamente 800 alunos, localizada em um bairro de classe média, em Belo Horizonte, há mais de 55 anos trabalhando com Educação Infantil, Ensino Fundamental e atualmente Ensino Médio. A biblioteca informou que desenvolve diversos projetos direcionados ao Ensino Fundamental $\mathrm{I}\left(1^{\circ}\right.$ ao $\left.5^{\circ}\right)$, visando incentivar o gosto pela leitura, ampliar a oralidade, a imaginação e a sensibilidade. Dentre os projetos, funciona ininterruptamente há nove anos o Clube da Leitura. A equipe do projeto, onde se incluem professores, reúne-se a cada quinze dias para discutir e planejar estratégias de incentivo e mediação da leitura dentro do ambiente da biblioteca, com os membros do Clube. A atividade é direcionada a alunos do Fundamental II e do Ensino Médio.

\subsection{Ferramentas de coletas de dados}

A realização do trabalho de campo utilizou a observação e a aplicação de entrevistas semiestruturadas. A pesquisa utilizou-se também dos princípios da etnografia, que permitem ao pesquisador entrar em contato com o universo estudado, compartilhando o horizonte dos sujeitos de pesquisa, mas não no intuito de "atestar a lógica de sua visão de mundo, mas para, seguindo-os até onde seja possível, numa verdadeira relação de troca, comparar suas próprias teorias com as deles e assim tentar sair com um modelo novo de entendimento" (MAGNANI, 2009, p. 135).

A etnografia pode combinar vários métodos de coleta de dados, como observação, participação, entrevistas mais ou menos formais, uso de documentos e outros traços de eventos na etnografia. Nem sempre um assunto relevante é acessível à etnografia e à observação participante. A amostragem, 


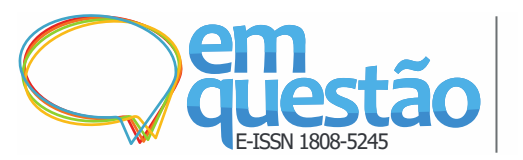

Adolescentes e mediação da leitura em biblioteca escolar Flávia Ferreira Abreu, Ligia Maria Moreira Dumont

neste contexto, é mais centrada no campo a ser pesquisado do que nas pessoas a serem selecionadas para a pesquisa.

\section{Análise dos dados}

No primeiro momento, foram realizadas conversas com os responsáveis pelas escolas expondo os objetivos da pesquisa. Após a aceitação da investigação nesses locais e assinatura do termo livre de consentimento ${ }^{7}$, as observações iniciaram-se em agosto de 2018 e as entrevistas em meados de setembro deste ano. O objetivo era: observar - tomar conhecimento das ações realizadas na biblioteca para trabalhar a leitura; entrevistar - com fins de relacionar os dados obtidos nessas duas ferramentas de coletas de dados; e continuar as observações - tendo em vista checar as informações adquiridas. Os dados foram analisados pelo ponto de vista etnográfico e imersão no campo de estudos, para acompanhar ações que tinham o viés de incentivar e mediar à leitura. A partir das observações e das informações adquiridas pelas entrevistas semiestruturadas, foram criadas categorias e subcategorias e a partir de pontos comuns, agrupou-se os dados para análise. Esses dados foram relacionados com o referencial teórico da pesquisa. Conforme salientado por Laville e Dione (1999), as categorias iniciais foram definidas a priori, de acordo com a literatura que conferiu embasamento a essa investigação e aos roteiros das entrevistas. As subcategorias refletem assuntos que estão nas entrelinhas das falas das entrevistadas. Isso permite que o pesquisador amplie seu campo de análise, contemplando dados relevantes da pesquisa (MOREIRA, 2014).

As entrevistas foram transcritas, e depois agrupadas nas seguintes categorias:

a) interação da coordenação pedagógica com a biblioteca;

Uma das primeiras questões apontadas por Campello (2009) e confirmadas em evento coordenado pela autora e coordenadora do Grupo de Estudos em Biblioteca Escolar - GEBE, em 2018, é a importância de se trabalhar o papel educador do bibliotecário em junção com a direção, coordenação e docentes da unidade de ensino. 


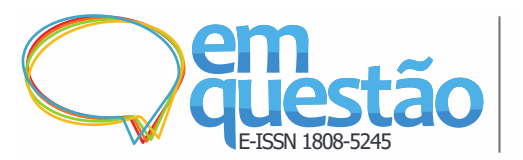

Adolescentes e mediação da leitura em biblioteca escolar Flávia Ferreira Abreu , Ligia Maria Moreira Dumont

Nomeou-se a subcategoria interação com os professores, pois se percebeu que existe uma presença maior do professor do que da coordenação pedagógica nas bibliotecas escolares estudadas, inclusive duas unidades de ensino têm forte presença dos docentes de história, que utilizam-se da literatura para ensinar os conteúdos e ir além desse objetivo, que é proporcionar uma leitura prazerosa e ampla para o leitor.

A bibliotecária da escola MB ressalta a dificuldade que passa para interagir com os professores de português, mas como ela percebe a importância de trabalhar com os docentes, foi criada uma nova estratégia para desenvolver ações na biblioteca em equipe com o professor, ou equipe pedagógica, que queira assumir de forma efetiva a apropriação da biblioteca como espaço de aprendizagem.

b) projetos em conjunto;

Com o objetivo de conhecer as ações desenvolvidas nas bibliotecas de incentivo e mediação à leitura, dois clubes da leitura referentes às escolas EP e MA tiveram suas ações acompanhadas de perto. O Clube da Leitura da EP é um projeto criado há nove anos, por iniciativa das professoras de produção de texto e história, em junção com a bibliotecária. O Clube da Leitura tem um caráter multidisciplinar, pois a leitura é retratada na visão da Filosofia, da Literatura, da História e da Biblioteconomia. De acordo com depoimentos, a existência do Clube do Livro em MA possibilitou aos alunos a construção de uma identidade, sentimento de pertencimento e apropriação do espaço da biblioteca, por compartilharem leituras. Essa combinação de mediação integrada e contextualizada torna rico o diálogo entre os participantes dos clubes da leitura das duas escolas.

c) mediar, incentivar e promover a leitura;

Os dados permitem que sejam visualizadas questões que permeiam o conceito de mediação e incentivo à leitura pelo viés que norteia determinada possibilidade do aluno se tornar um leitor, por meio do incentivo da escola, de ações organizadas que possibilitam a interação do leitor, texto e o diálogo com os leitores. Já a promoção da leitura é compreendida a partir de ações que vão 


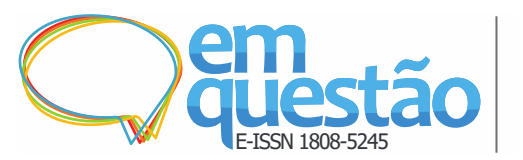

Adolescentes e mediação da leitura em biblioteca escolar Flávia Ferreira Abreu , Ligia Maria Moreira Dumont

ampliar o contato coletivo com o livro e com atividades de mediação e incentivo à leitura.

Acredita-se que para promover a leitura, o bibliotecário e o professor precisam dar acesso ao livro e à informação, fomentando ações que possibilitem o contato com as diversas formas de leitura. A partir desse momento, o mediador interage com o leitor para construir um diálogo sobre a leitura, planejado e baseado em bases teóricas, que auxiliem o processo do encontro do leitor com texto em sua essencialidade, dando-se a mediação e o incentivo à leitura. Mediar e incentivar é mais amplo que promover, embora se use os termos de forma semelhantes, aleatoriamente, mas há diferenças sutis:

- mediar e incentivar leitura: ler o livro e indicá-lo para outros leitores, tornar a história interessante para o leitor, discuti-la, fazer questionamentos, mostrar os benefícios que a leitura oferece e o poder de transformação que tem;

- promover: fomentar; incentivar: estimular ${ }^{8}$.

Por fim, a análise dos conceitos e a devida contextualização deles demonstram - em conjunto com os relatos oriundos de vivência prática - que tais ações possuem significados distintos, embora permaneçam relacionados e complementares, não só pelos sujeitos da pesquisa.

d) gosto pela leitura;

O gosto pela leitura é entendido como prazer que se tem ao ler e conversar sobre as diversidades de leitura. Para compreender a questão do gostar, as entrevistadas fazem uma associação com outros gostos que o sujeito demonstra ter. As entrevistadas relacionam o gosto pela leitura a partir de um olhar abrangente, em que não há preconceito com o que se ler. Os sujeitos da pesquisa não acreditam que as pessoas não gostam de ler, ressaltam que pelo menos um jornal ou uma revista são fontes de prazer para o leitor.

Efetivamente, o leitor pode não ter encontrado sua leitura preferida, mas há grande possibilidade que este encontro aconteça e se desenvolva quando se tem o exemplo da família, da escola, ou de um colega. Uma entrevistada 


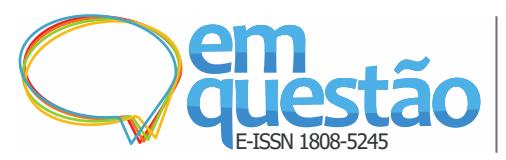

Adolescentes e mediação da leitura em biblioteca escolar Flávia Ferreira Abreu, Ligia Maria Moreira Dumont

confirmou tal premissa quando expressou que com o incentivo, sem o exemplo, o gosto pela leitura é muito difícil de ser despertado. "Você tem que ter exemplo de pessoas que você admira que sejam leitores e que lhe leve a ter contatos com os livros, que fale que ler é legal, mostre em obras", pois, possivelmente sem o exemplo não adianta.

e) formação do leitor;

Nesse quesito de análise, pôde-se observar que os sujeitos da pesquisa relacionam a formação do leitor com a competência que o educador, seja professor ou bibliotecário, tem para auxiliar no processo de construção do leitor. Percebeu-se nas falas que os agentes formadores da leitura utilizam-se da intertextualidade para apresentar novas leituras e possibilitar o amadurecimento do leitor. O auxílio da família, o ato de ler juntos e compartilhar leituras e experiências de se ler, são essenciais desde o início da infância para a formação do leitor, como é ressaltado no referencial teórico dessa pesquisa e confirmado pelos depoimentos das entrevistadas.

A rede de formação e integração de leitores, conduzida pelo estímulo que um exerce sobre o outro, é confirmada por meio do sucesso alcançado com os clubes da leitura analisados na pesquisa, pois, nestes projetos, foi permitido o diálogo entre os leitores para conhecer o prazer e as formas de leitura, mediados pela escola.

f) leitores críticos;

Ao se falar da formação do leitor, não é possível deixar de referenciar o leitor crítico, que procura entender as entrelinhas dos textos, questionar, argumentar, refletir sobre o que lê e fazer suas interpretações. Para os sujeitos da pesquisa é fundamental formar esse leitor, educar o aluno no sentido de desenvolver o senso crítico para interpretar as escritas, as leituras, as falas, as informações nas diversas modalidades que se manifestam para o leitor. Essa não é uma missão simples de ser alcançada, afirmaram, no entanto, o bibliotecário e o professor, mas como educadores que são, podem trabalhar em equipe e auxiliar os alunos a desenvolver essa habilidade. 


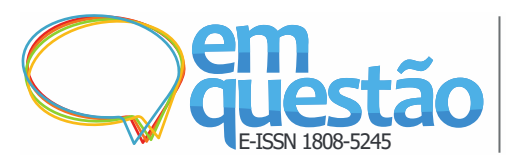

Adolescentes e mediação da leitura em biblioteca escolar Flávia Ferreira Abreu, Ligia Maria Moreira Dumont

Nesse sentido, a bibliotecária da escola (MB) acredita que a mediação dá a possibilidade de o leitor, frente ao texto escrito ou imagético, fazer as suas inferências. O aluno tem que formar e dar sentindo aquilo que leu. Essa entrevistada relatou que as leituras são subjetivas e o leitor vai reagir positivamente ou negativamente ao contato com a literatura, muitas vezes relacionando ao seu contexto social. Na fala da mediadora de leitura, percebe-se que ao apresentar um texto para o leitor, é importante que se conheça a realidade desse sujeito. Por exemplo, foi apresentada a contação de história muito afetiva que retratava a relação de pai e filho. Ao final desse momento de leitura, observou-se que um aluno não estava interagindo com aquela atividade, porque "ele estava com uma questão muito complexa com o pai dele, os pais tinham se separado e a relação entre eles era muito difícil” (BIBLIOTECÁRIA MB). As ações para construir a formação do leitor precisam ser planejadas e deve-se levar em conta o público que irá interagir com essa atividade, pois ao invés de aproximar esse leitor da literatura o efeito pode ser o contrário. Por isso, continua a entrevistada: "se eu medeio, tenho que estar preparada para incentivar o debate e trocar experiências com os pares".

O letramento informacional é reconhecido pelos entrevistados, e as ações relatadas refletem, nas entrelinhas das entrevistas, tal preocupação. Entretanto, apesar da inquietação com o letramento e a formação de um leitor crítico, não há ações planejadas especificamente para esta competência nas três bibliotecas pesquisadas.

g) leitor e suas leituras atuais;

Essa categoria foi essencial para a investigação, todos os sujeitos da pesquisa se consideram leitores, e o mais interessante, ao serem questionados sobre o que estão lendo, três pessoas responderam que a atividade de leitura não está tão ativa, pois estão se dedicando a leituras técnicas para formação e desenvolvimento do trabalho nas escolas. É visível a relação que estabelecem com o leitor, apenas com a leitura de fruição.

A leitura permeia por diversos campos dos sujeitos da pesquisa, pois estão sempre lendo informações atuais, tanto para estar atualizados ao trabalho 


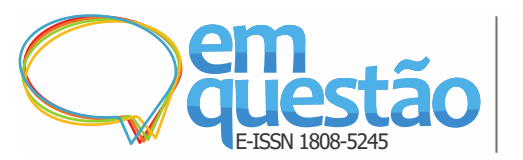

Adolescentes e mediação da leitura em biblioteca escolar Flávia Ferreira Abreu , Ligia Maria Moreira Dumont

ou para sugerirem para os alunos a leitura de obras infantis, juvenis e/ou direcionadas a um público adulto. O clube da leitura impulsiona a ler mais, porque os profissionais envolvidos com a leitura, mediação e incentivo precisam estar atentos ao contexto de vida dos leitores, no intuito de transmitir o texto e incentivar a análise própria dessa conjuntura, de forma abrangente. As bibliotecas lidam com todos os alunos, tanto crianças nos anos iniciais ou finais. Logo, manifestam-se leitores formados ou em formação, o que exige dos profissionais um conhecimento profundo referente aos textos e os leitores.

\section{Considerações finais}

O objetivo principal desta pesquisa foi conhecer as ações de mediação e incentivo à leitura, desenvolvidas nas bibliotecas escolares que oferecem classes a partir do quinto período, especificamente na cidade de Belo Horizonte, Minas Gerais. Em uma biblioteca municipal e outra particular constatou-se a existência de um projeto contínuo, o clube de leitura e, nas três, há presença de ações sazonais de mediação e incentivo à leitura, que são elaboradas e trabalhadas em conjunto com os professores e a equipe da biblioteca.

Chamou a atenção o fato de seis entrevistados queixarem-se de que nem todos os professores de português estão abertos ao trabalho em colaboração com a biblioteca. Uma sutileza: só reclamaram da falta do professor de português, ou seja, ainda há um certo mito entre os bibliotecários e suas equipes, de que a biblioteca tem por objetivo precípuo a formação de leitores proficientes em leitura literária. Um exemplo, como a equipe da biblioteca MB é muito proativa, convidou outros docentes para assumirem esse lugar considerado do professor de português. A parceria tem se concretizado, integrando diferentes profissionais como historiadores, filósofos e produtores de texto ao ambiente da biblioteca.

$\mathrm{Na}$ escola MB, os empréstimos, orientações de leitura e contação de história são constantes na biblioteca. A bibliotecária esclareceu que a contação é importante, embora não seja a única estratégia relacionada à leitura nas bibliotecas escolares. 


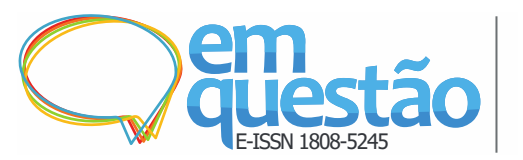

Adolescentes e mediação da leitura em biblioteca escolar Flávia Ferreira Abreu , Ligia Maria Moreira Dumont

As escolas MA e EP, além das atividades supracitadas, desenvolvem a contação de história e o projeto permanente Clube do Livro e o Clube da Leitura, que têm como objetivos compartilhar leituras, por meio do contato com mediadores, escritores, livros e filmes que possibilitam a interação com a literatura, a partir do prazer de ler. Os clubes da leitura permitem a participação ativa dos alunos a eventos de leitura, atividades essas consideradas por Carvalho (2016) como uma fonte de aprendizagem.

A pesquisa constatou o fato de serem muito poucas as atividades de motivação da leitura planejadas para alunos adolescentes. O mais contraditório e, portanto, desafiador, é que é a partir desta faixa que boa parcela das crianças deixa de frequentar as bibliotecas escolares. Porém, a prática clube de leitura mostrou-se um exemplo de grande aceitação e longevidade em duas bibliotecas. Torna-se também interessante lembrar, que agora os clubes de leitura ganharam a possibilidade de acontecerem via internet. Relatos de profissionais e pesquisa estão mostrando essa realidade.

Para fechar, reafirma-se uma questão da maior importância: o ato de ler recebe interferências de fatores externos do contexto de vivência do leitor, como a cultura, as relações sociais, e internos, os quais envolvem, fatores cognitivos e afetivos; ambos vão interferir na atribuição de valores e compreensão do mundo. A partir dessa afirmação, é possível perceber que a formação do leitor crítico constitui-se de processo complexo; logo, o bibliotecário mediador, além de ser leitor, deve conhecer o contexto social dos seus leitores, além de estar a par dos estudos e pesquisas sobre o tema. Não esquecendo que sendo gestor ou não, precisa planejar e ter aprovado pela instância superior e os coparticipantes do plano as atividades que irá desenvolver para a comunidade escolar, observandose as especificidades dos sujeitos integrantes daquele contexto social e cultural.

\section{Referências}

ABREU, F. F. Mediação e leitura na biblioteca escolar: estudo de casos múltiplos. 2019. 124 f. Dissertação (Mestrado em Ciência da Informação) Escola de Ciência da Informação, Universidade Federal de Minas Gerais, Belo Horizonte, 2019. 


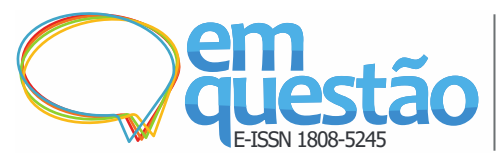

Adolescentes e mediação da leitura em biblioteca escolar Flávia Ferreira Abreu , Ligia Maria Moreira Dumont

ALMEIDA JÚNIOR, O. F. Leitura, mediação e apropriação da informação. In:

SANTOS, J. P. (org.). A leitura como prática pedagógica: na formação do profissional da informação. Rio de Janeiro: Fundação Biblioteca Nacional, 2007. p. 3345 .

ALMEIDA JÚNIOR, O. F.; BORTOLIN, S. Bibliotecário: um essencial mediador de leitura. In: SOUZA, R. J. (org.). Biblioteca escolar e práticas educativas: mediador em formação. Campinas: Mercado de Letras, 2009. p. 205-218.

ANTUNES, I. Aula de português: encontro \& interação. São Paulo: Parábola Editorial, 2003.

ARAÚJO, C. A. Á. Novo quadro conceitual para a ciência da informação: informação, mediações e cultura. In: ENCONTRO NACIONAL DE PESQUISA EM CIÊNCIA DA INFORMAÇÃO, 17., 2016, João Pessoa. Anais eletrônicos [...]. João Pessoa: Ancib, 2016. p. 1-17.

BARROS, M. H. T. C.; BORTOLIN, S.; SILVA, R. J. Leitura: mediação e mediador. São Paulo: Ed. FA, 2006.

BORTOLIN, S. Mediação oral da literatura: a voz do bibliotecário lendo ou narrando. 2010. 233 f. Tese (Doutorado em Ciência da Informação) - Faculdade de Filosofia e Ciências, Universidade Estadual Paulista, Marília, 2010.

BORTOLIN, S.; ALMEIDA JÚNIOR, O. F. O leitor-narrador, o leitor-ouvinte e o bibliotecário na floresta literária. In: CONGRESSO DE LEITURA DO BRASIL, 17., Campinas, 2009. Anais eletrônicos [...] Campinas: ALB, 2009.

BICHERI, A. L. A. O.; ALMEIDA JÚNIOR, O. F. Bibliotecário escolar: um mediador de leitura. Biblioteca Escolar em Revista, Ribeirão Preto, v. 2, n. 1, p. 41-54, 2013.

BRITTO, L. P. L. Ao revés do avesso: leitura e formação. São Paulo: Pulo do Gato, 2015.

CAMPELLO, B. S. Letramento informacional no Brasil: práticas educativas de bibliotecários em escolas de ensino básico. 2009. 208 f. Tese (Doutorado em Ciência da Informação) - Escola de Ciência da Informação, Universidade Federal de Minas Gerais, Belo Horizonte, 2009.

CARVALHO, M. C. Educação e criatividade: repensando papel dos mediadores de leitura. In: AMARILHA, M. (org.). Educação e leitura: desafios e criatividade. Campinas: Mercado de Letras, 2016. p. 101-112.

CAVALLO, G.; CHARTIER, R. Introdução. In: CAVALLO, G.; CHARTIER, R. (org.). História da leitura no mundo ocidental. São Paulo: Ática, 1998. v. 1.

CECCANTINI, J. L. Leitores iniciantes e comportamento perene de leitura. In: SANTOS, Fabiano dos; MARQUES NETO, José Castilho; ROSING, Tânia Mariza Kuchenbecker. Mediação de leitura: discussões e alternativas para a formação de leitores. São Paulo: Global, 2009. 


\section{DUMONT, L. M. M. O imaginário feminino e a opção pela leitura de} romances em série. 1998. 256 f. Tese (Doutorado em Comunicação e Cultura). Escola de Comunicação da Universidade Federal do Rio de Janeiro/Instituto Brasileiro de Informação em Ciência e Tecnologia, Rio de Janeiro, 1998.

DUMONT, L. M. M. Leitura, via de acesso ao conhecimento: algumas reflexões. In: SANTOS, J. P. (org.). A leitura como prática pedagógica: na formação do profissional da informação. Rio de Janeiro: Fundação Biblioteca Nacional, 2007. p. 65-76.

FÉLIX, A. F. Práticas educativas em bibliotecas escolares: a perspectiva da cultura escolar: uma análise de múltiplos casos na RME/BH. 2014. $124 \mathrm{f}$. Dissertação (Mestrado em Ciência da Informação) - Escola de Ciências da Informação, Universidade Federal de Minas Gerais, Belo Horizonte, 2014.

FREIRE, P. A importância do ato de ler: em três artigos que se completam. 23. ed. São Paulo: Cortez: Autores Associados, 1989.

\section{LAKATOS, E. M.; MARCONI, M. A. Fundamentos de metodologia científica. São Paulo: Atlas, 1996.}

LAVILLE, C.; DIONNE, J.; SIMAN, L. M. C. A construção do saber: manual de metodologia da pesquisa em Ciências Humanas. Porto Alegre: Artmed, 1999.

MAGNANI, J. G. C. Etnografia como prática e experiência. Horizontes Antropológicos, Porto Alegre, v. 15, n. 32, p. 129-156, jul./dez. 2009.

MARTELETO, R. M. Jovens, violência e saúde: construção de informações nos processos de mediação e apropriação de conhecimentos. Revista Eletrônica de Comunicação, Informação, Inovação e Saúde, Rio de Janeiro, v.3, n.3, p.1724, set. 2009.

MARTELETO, R. M.; COUZINET, V. Mediações e dispositivos de informação e comunicação na apropriação de conhecimentos: elementos conceituais e empíricos a partir de olhares intercruzados. Revista Eletrônica de Comunicação, Informação e Inovação em Saúde, Rio de Janeiro, v. 7, n. 2, p. 1-16, jun. 2013.

MARTINS, E. A revitalização das bibliotecas escolares na rede municipal de ensino: espaços de mediação de leitura. 2005. Trabalho de Conclusão de Curso (Graduação em Biblioteconomia) - Departamento de Ciência da Informação, Universidade Estadual de Londrina, Londrina, 2005.

MINAYO, M. C. S. (org.). Pesquisa social: teoria, método e criatividade. 29. ed. Petrópolis: Vozes, 2009.

MOREIRA, J. A. Práticas educativas bibliotecárias de formação de leitores: um mapeamento de suas iniciativas e articulações na Rede Municipal de Ensino de Belo Horizonte (RME-BH). 2014. 123f. Dissertação (Mestrado em Ciência da Informação) - Escola de Ciência da Informação, Universidade Federal de Minas Gerais, Belo Horizonte, 2014. 


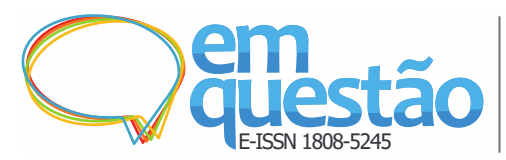

Adolescentes e mediação da leitura em biblioteca escolar Flávia Ferreira Abreu , Ligia Maria Moreira Dumont

NUNES J. V.; CAVALCANTE, L. E. Mediação, circulação e apropriação da Informação: por uma epistéme mediacional na Ciência da Informação. In: ENCONTRO NACIONAL DE PESQUISA EM CIÊNCIA DA INFORMAÇÃO, 18., Marília, 2017. Anais eletrônicos [...]. Marília: Ancib, 2017. Não paginado.

PEREIRA, G.; CAMPELLO, B. S. Compreendendo a colaboração entre bibliotecário e professor: a contribuição dos estudos de Patricia Montiel-Overall e do modelo TLC. Brazilian Journal of Information Science: research trends, Marilia, v. 10, n.2, p. 4-14, 2016.

RASTELI, A. Mediação da leitura em bibliotecas públicas. 2013. 169 f. Dissertação (Mestrado em Ciência da Informação) - Faculdade de Filosofia e Ciências, Universidade Estadual Paulista, Marília, 2013.

SILVA, E. T. O professor e o combate à alienação imposta. São Paulo: Cortez: Autores Associados, 1991.

SOARES, M. Letramento: um tema em três gêneros. 3. ed. Belo Horizonte: Autêntica, 2009.

TURRA, N. C. Reuven Feuerstein: experiência de aprendizagem mediada: um salto para a modificabilidade cognitiva estrutural. Educere et Educare Revista de Educação, Cascavel, v. 2, n. 4, p. 297-310, jul./dez. 2007.

VYGOTSKY, L. S. Pensamento e linguagem. São Paulo: Martins Fontes, 1993.

\title{
Teenagers and reading mediation in the school library
}

\begin{abstract}
The research investigated the mediation and reading incentive actions that are used by school library teams in order to train readers. The objective was to analyze the work of the school librarian who develops these actions in his way of operating, contributing to the formation of critical subjects and with a taste for reading. Methodologically, a multiple case study was undertaken, with a qualitative approach, based on the point of view of ethnographic theory. In data collection, the research environment was represented by three school libraries, one from private education, and the others belonging to the municipal public network in the city of Belo Horizonte MG, which serves elementary school students from the fifth year onwards. Observation and semi-structured interviews were used for data collection, which had as research subjects the librarians and teachers who participate in these actions. The research found that mediation and incentive activities are effective when the mediator is a reader and remains open to continuous dialogue with his users and with other instances of the school. It was found that the most successful and long-lived actions of training the reader in the three libraries were those of mediation promoted by the uninterrupted meetings of the reading clubs, whose participants come together to share readings chosen by them, for the pleasure of reading. The analyzed libraries have mediation and reading incentive projects with the participation of teachers and librarians. The novelty was the presence of teachers from other disciplines, who proved to be great mediators of reading. It was also found what several authors in the field proclaim that librarian and teacher are trainers of readers. In the specific case of the research, they are
\end{abstract}




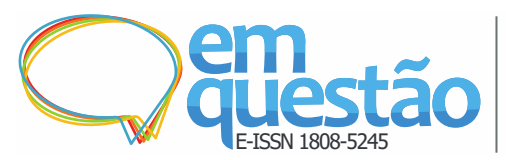

Adolescentes e mediação da leitura em biblioteca escolar Flávia Ferreira Abreu , Ligia Maria Moreira Dumont

knowledgeable about literature for children and adolescents, the authors, literary genres and, mainly, plan to share the readings, as a possibility to train critical and contextualized readers with their society.

Keywords: Reading mediation. Teenagers. School library. Critical reader. Collaboration librarian-teacher. Reading clubs.

Recebido: $11 / 05 / 2020$

Aceito: 06/07/2020

\section{Declaração de autoria}

Concepção e elaboração do estudo: Flávia ferreira Abreu, Ligia Maria Moreira Dumond

Coleta de dados: Flávia ferreira Abreu, Ligia Maria Moreira Dumond Análise e discussão de dados: Flávia ferreira Abreu, Ligia Maria Moreira Dumond

Redação e revisão do manuscrito: Flávia ferreira Abreu, Ligia Maria Moreira Dumond

\section{Como citar}

ABREU, Flávia Ferreira; DUMONT, Ligia Maria Moreira. Adolescentes e mediação da leitura em biblioteca escolar. Em Questão, Porto Alegre, v. 27, n. 1, p. 388-402, jan/abr. 2021. Doi: http://dx.doi.org/10.19132/18085245271.388-402

1 O artigo teve como referencial a dissertação de Flávia Ferreira Abreu.

2 GELLEREAU, M. Pratiques culturelles et médiation. In: OLIVESI, S. Sciences de I'Information et de la Communication: objets, savoirs, discipline. Grenoble: Presses Universitaires de Grenoble, 2006. p. 27-42 apud Marteleto (2009).

3 Escola Municipal A.

${ }^{4}$ Biblioteca matriz, local em que o (a) bibliotecário (a) é lotado e acompanha mais quatro outras bibliotecas, com visitas regulares.

5 Escola Municipal B.

${ }^{6}$ Escola Particular.

7 Aspectos éticos: a pesquisa foi aprovada pelo Parecer Consubstanciado do Comitê do Comitê de Ética em Pesquisa da UFMG (CEP-UFMG), em setembro de 2018, número 2395603. As entrevistadas assinaram o Termo de Consentimento Livre (TCL) e Esclarecido, aprovado pelo CEP-UFMG.

8 Disponível em: https://dicionario.priberam.org/promover. Acesso em: 24 jan. 2019. 